\title{
A SAFETY PROTECTION DEVICE FOR BYPASS CAPACITOR OF THE WHITE CIRCUIT
}

\author{
Chen-Yao Liu, Hsu-Ming Shih, Kuo-Bin Liu \\ National Synchrotron Radiation Research Center, Hsinchu, 30076, Taiwan, R.O.C.
}

\section{Abstract}

This paper presents a new safety protection system for the bypass capacitor in the white circuit. In general, if the operation current of the white circuit deviates too much, the injection efficiency will be deteriorated and the white circuit bypass capacitor will be hurt. In order to detect the dynamic characteristics of the bypass capacitor to achieve protection function, the new protection system is proposed in this paper. The experimental results show that new protection system not only can monitor and detect the dynamic voltage and current of the bypass capacitor of the white circuit, but also prevent this bypass capacitor from being damaged.

\section{INTRODUCTION}

In general, the Taiwan Light Source (TLS) is composed of a storage ring and a booster system [1]. In order to accelerate the beam energy of the booster ring from $50 \mathrm{MeV}$ to $1.5 \mathrm{GeV}$, the white circuit [2] can be applied, as shown in Figure 1. When used an electrolyte capacitor which is polarized to be the bypass capacitor, the bypass capacitor will be damaged or detonated when an opposite polarity or over current situation occurs $[3,4]$. In another words, the operation voltage and current of the bypass capacitor in the white circuit should be in the first quadrant with $10 \mathrm{~Hz}$ resonant frequency to work in normal condition. Figure 2 shows the bypass capacitor of the white circuit in TLS. Generally speaking, in order to protect the bypass capacitor in the white circuit when the operation voltage and current are not in the first quadrant, the protection system is needed. In addition, due to the high voltage and current are operated in the booster ring; a good deal of noise may interact with the protection system.

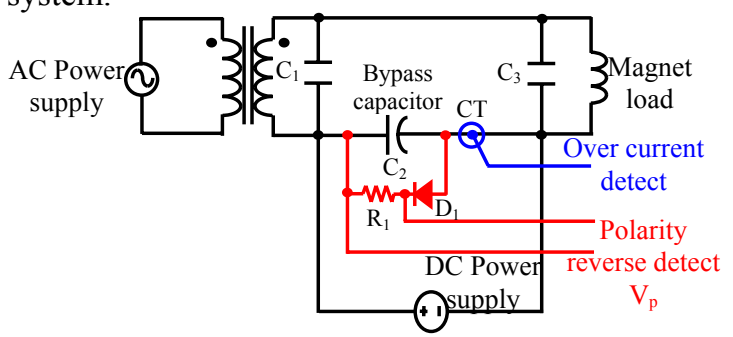

Figure 1: The white circuit and the detection part of the protection system.

Therefore, the new protection system presents in this paper not only can turn on the interlock system and cutoff the related power supply when an error condition is detected, but also can bypass the protection system when the noise interact with the protection system. In the booster ring, there are three protection circuits for Dipole,
Focus Quadrupole (FQ) and Defocus Quadrupole (DQ) magnet to monitor the dynamic current and to preserve the bypass capacitor.

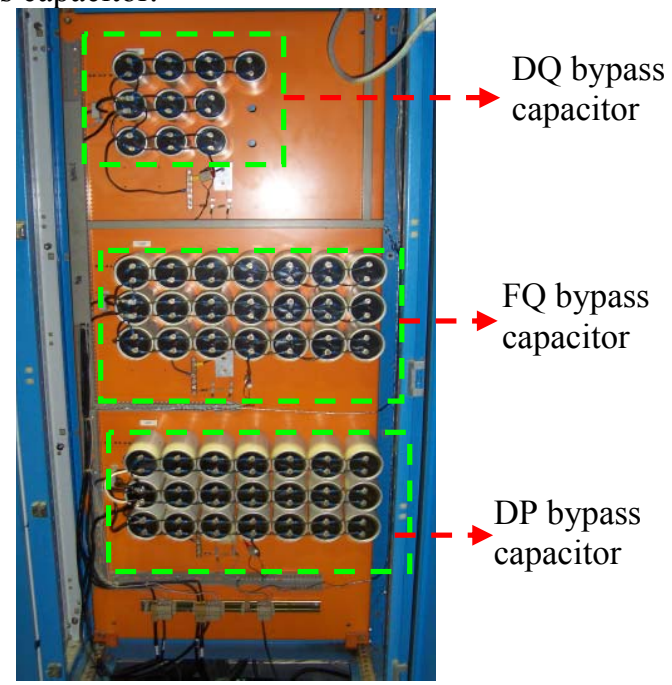

Figure 2: The bypass capacitor of the white circuit.

\section{DESIGN AND IMPLEMENTATION OF THE PROTECTION CIRCUIT}

The operation voltage and current of the bypass capacitor of the white circuit can be monitored and observed as shown in Figure 1. Then, in Figure $1, \mathrm{C}_{2}$ is the white circuit bypass capacitor and we are going to protect. Based on the monitor results, the protection system can be worked. The main protection is shown in Figure 3, and the protection system is shown in Figure 4.

\section{Over Current}

As shown in Figure 5, the CT is installed across to the capacitor $\mathrm{C}_{2}$ to detect current as shown in Figure 6 . When the current of the bypass capacitor is over then the working point in the circuit design, the bypass capacitor will be damaged. For this reason, the CT is needed as a protection device to avoid the over current event. When the over current event is occurred, in Figure 3, the voltage $\mathrm{V}_{1}$ is larger than $\mathrm{V}_{2}$, and the output of the operational amplifier (OPA) $\mathrm{U}_{1}$ is high state. Therefore, the relay $\mathrm{K}_{1}$ is turned on and $\mathrm{K}_{2}$ is turned off, then voltage $\mathrm{X}_{1}$ is high and the magnet power supply will be turned off. In general, according to the experience, the up-limit of the bypass capacitor current can be decided by turning the resistor $R_{x}$.

\section{Polarity Reverse}

Diode $\mathrm{D}_{1}$ and $\mathrm{R}_{1}$ form a voltage detector in Figure 7 . Therefore, the voltage across the bypass capacitor can be 


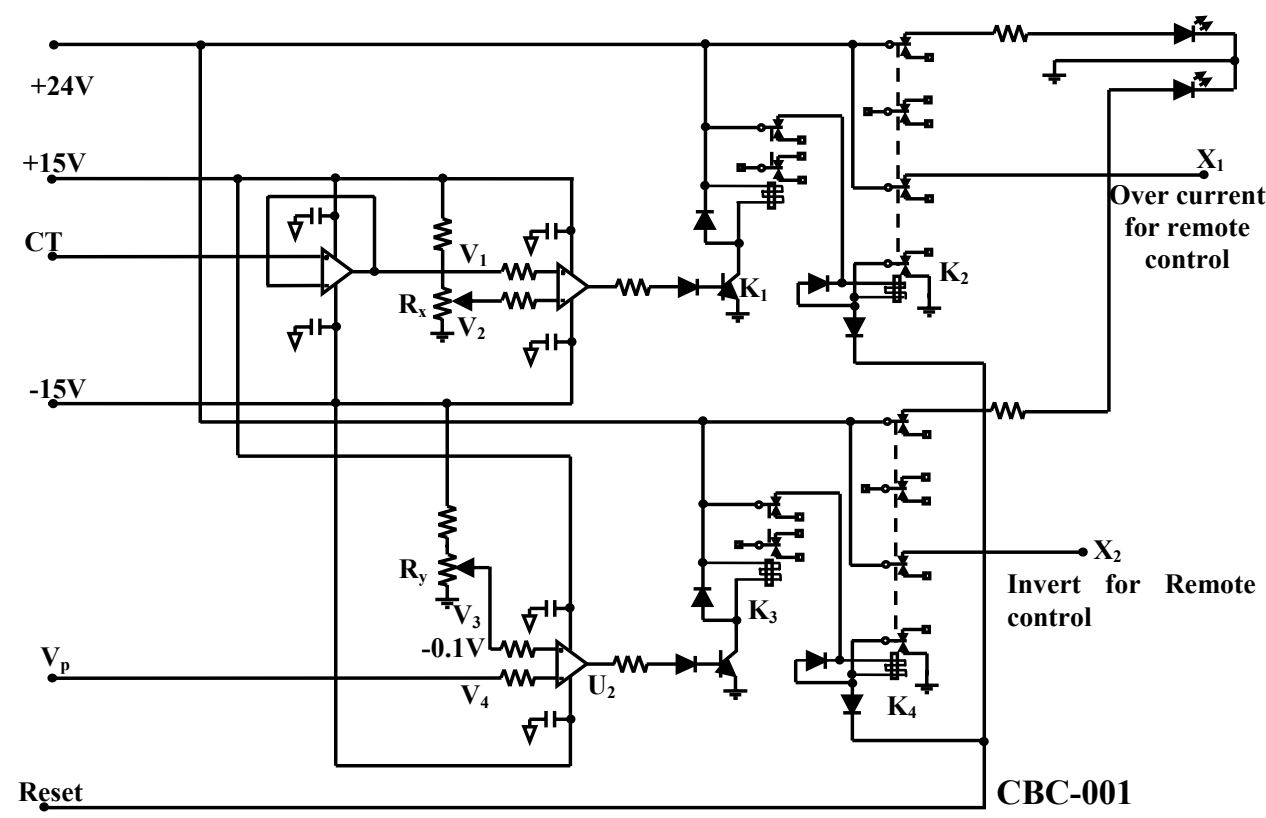

Figure 3: The protection circuit for bypass capacitor of the white circuit.

measured, as shown in Figure 8. When the voltage across to the bypass capacitor is reversed, then the electrolyte capacitor $\mathrm{C}_{2}$ will be damaged. In Figure 3 , when the polarity reverse event is happened, the voltage $V_{3}$ is larger than $\mathrm{V}_{4}$, and the output of the OP $\mathrm{U}_{2}$ is high state. Therefore, the relay $\mathrm{K}_{3}$ is turned on and $\mathrm{K}_{4}$ is turned off, then the voltage $\mathrm{X}_{2}$ is high and the magnet power supply will be turned off. Due to the bypass capacitor module of the white circuit is in the radiation safety (RS) area and the power supply is in the operation area, it is difficult to turn-off the power supply and trouble shooting within a short time. Therefore, the protection system is separated to two parts: one is the local detection box in the radiation safety area as shown in Figure 9, and another is the remote control box in the outside operation (OP) area as shown in Figure 10.

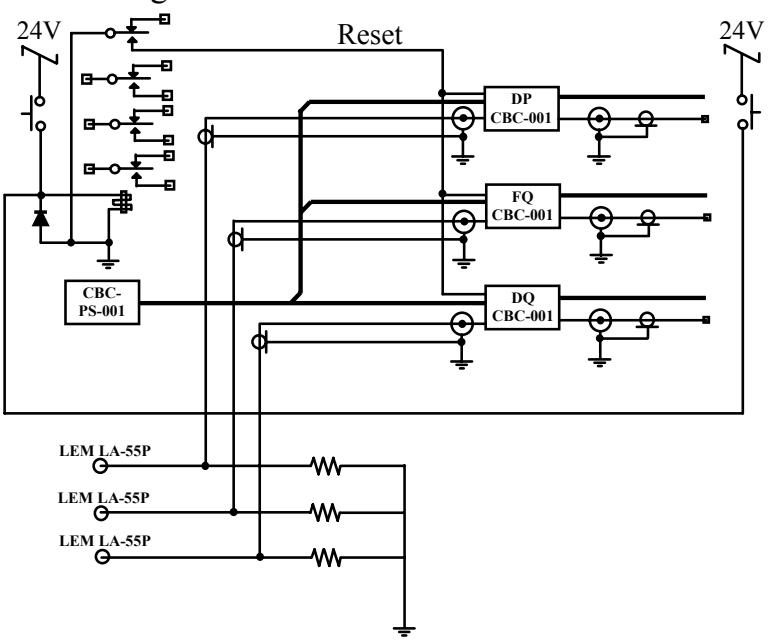

Figure 4: The white circuit bypass capacitor protection system block diagram.
The over current and polarity reverse can be monitored by the local detect box, and then the power supply can be turned off after the remote box receive the alarm signal from the local box. In addition, due to the high voltage and current are operated in the booster ring; a good deal of noise may interact with the protection circuit. In order to avoid the wrong action by the noise interference, the bypass function is added to the protection system in the remote box. After turn on the bypass tuner as shown Figure 10, the bypass capacitor will have no protection until turn off the bypass turner.

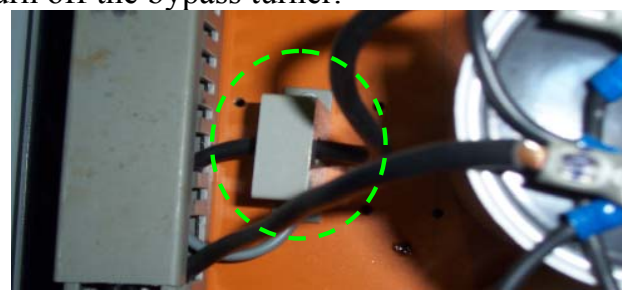

Figure 5: The CT to detect current of the bypass capacitor.

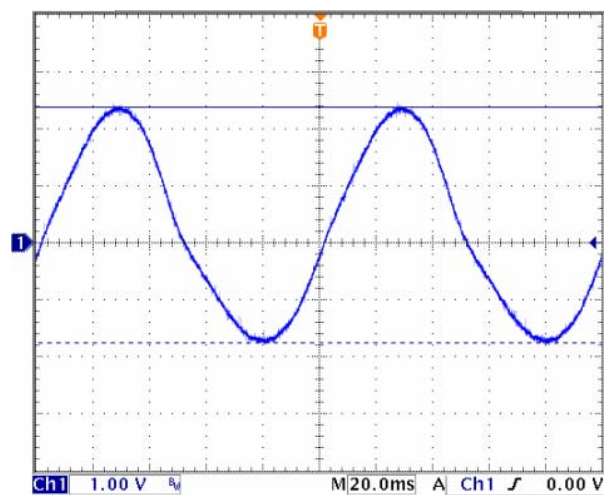

Figure 6: The measured current of the bypass capacitor of the DP. (Current sensor output: $5 \mathrm{~A} / \mathrm{V}$ ) 


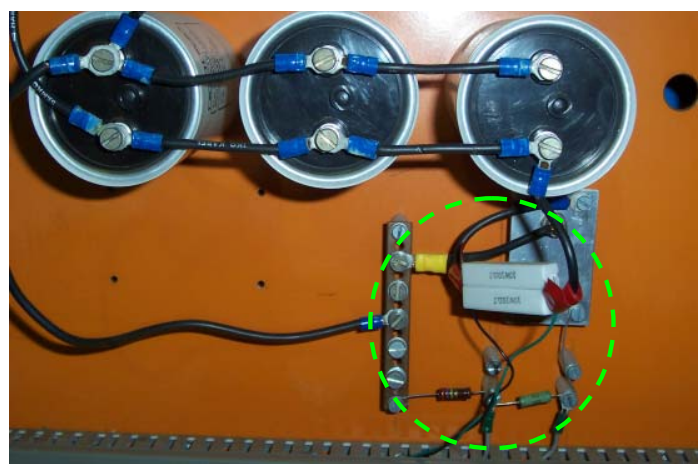

Figure 7: The voltage detector to observe the voltage of the bypass capacitor.

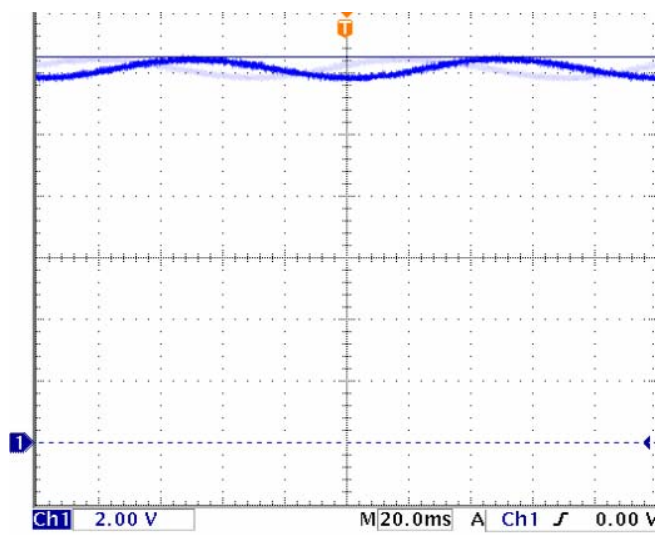

Figure 8: The measured voltage of the bypass capacitor of the DP. $(10 \mathrm{~V} / \mathrm{div})$.

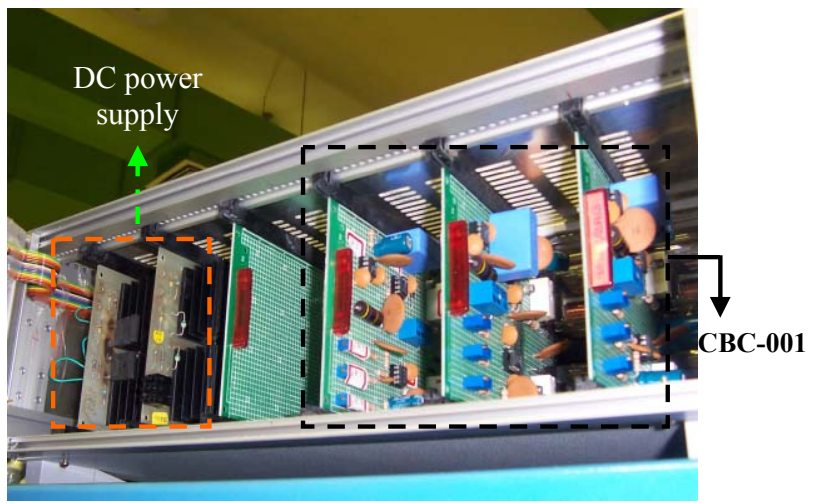

Figure 9: The local detection box in the RS area..

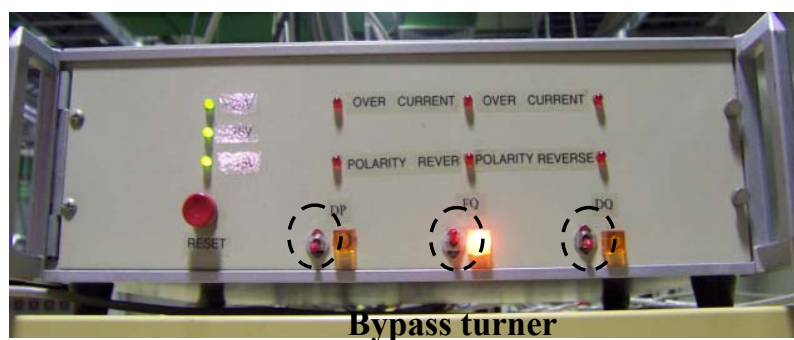

Figure 10: The remote control box in the OP area.

\section{CONCLUSION}

This paper has proposed a safety protection system for the bypass capacitor in the white circuit. Generally speaking, if the operation current of the bypass capacitor in the white circuit deviates too much or the voltage across the bypass capacitor becomes reverse, the bypass capacitor and the injection efficiency will be deteriorated and the white circuit bypass capacitor will be hurt. Therefore, in order to measure the dynamic characteristics of the bypass capacitor is very important. To achieve protection function, a safety protection device is proposed in this paper. The protection system proposed in this paper not only can avoid the breaking of the bypass capacitor, but also can bypass the protection function when the wrong interlock action due to the noise.

\section{REFERENCES}

[1] Preliminary Report On The Beam Optics And Conceptual Design of the BESSY $800 \mathrm{MeV}$ Booster Synchrotron by SCANDITRONIX 20, Sept 1978.

[2] R. Richter and S. Shaphir, "A status report on the examination of the proposed White-circuit", Feb 1979.

[3] K. Elmquist, "Study of methods to reach tracking specifications between magnetic fields in the SRRC Synchrotron" SCANDITRONIX, 1989

[4] C.Y. Liu, Justin Chiou, Y.C. Chien, J.A. Li, and J. T. Sheu, "Design and Implementation of the White Circuit Bypass Capacitor Protection System", European Particle Accelerator Conference (EPAC), Paris, France (2002). 